\title{
Education for Teacher Librarians in Germany
}

\author{
Nancy Everhart, Ph.D. \\ Florida State University, iSchool, USA
}

\begin{abstract}
This study identifies human perceptions and concerns regarding readiness for teacher library education in Germany (where it currently does not exist) by measuring the perceptions of 183 library science educators, library school students, and librarians in Berlin, Potsdam and Leipzig. The Concerns Based Adoption Model (CBAM) theory and methodology was used to measure these perceptions. The participants deem teacher librarianship education to be very much needed and that it could be incorporated into existing library education programs by introducing 2-3 specific courses. The German library community is enthusiastic about the possibility this education could provide to its students and plan to get involved personally or recommend it to others.
\end{abstract}

Keywords: Germany, Concerns Based Adoption Model (CBAM), teacher librarian education, school library education, school libraries, Programme for International Student Assessment (PISA)

\section{INTRODUCTION}

Various education reforms have been proposed and implemented in reaction to Germany's Programme for International Student Assessment (PISA) rankings over the past decade and a half (Organisation for Economic Co-operation and Development (OECD), 2010). However, one that has been yet to be systematically investigated is how effective teacher library programs could help to increase achievement test scores in Germany as they have in other countries. Since PISA assessments evaluate the wider knowledge and skills needed to participate in social, economic and political life in modern society German librarians responded swiftly to the first PISA results maintaining that PISA was visible proof for the importance of school libraries where problem-solving and self-directed learning occur (Krüger, 2003). Professional library associations in Germany pointed to Finland's success in PISA (Krolak, 2005) whereby Finnish students tend to use libraries more often than students from the other OECD countries (Linnakyla \& Valijarvi, 2005).

Despite the potential for school libraries to positively impact PISA scores, it is estimated that less than ten percent of pupils in Germany have access to a library staffed by a professional teacher librarian (Giersberg, 2012). 73\% of German students never use the school library - the highest percentage for the countries included in an OECD (2010) study. Reasons for this have included the use of public libraries (Krüger, 2003), reliance on textbooks (Döbert \& Sroka, 2004) and the lack of legal norms and standards (Weishaupt et. al, 2013). I have posited that the absence of school libraries might be a result of the related absence of teacher librarianship education in Germany (Everhart, 2009). In order to move forward in developing this education, a research study that identifies human perceptions and concerns regarding readiness for teacher library education was conducted.

Although decisions about educational innovations, such as new coursework, are frequently dependent on higher levels of authority rather than on an individual, the actual implementation of innovation is applied on a personal level (Hord, et. al, 2006; Straub, 2009). Therefore, when one attempts to understand the adoption of innovation, it is necessary to ask certain questions: Is teacher librarianship education desired in Germany? How does an individual feel about it? What are the roles of social contexts in this decision? Based on the importance of individuals and their adoption patterns, the research-based Concerns Based Adoption Model (CBAM) provides both a theoretical framework and methodology to identify individuals' levels of concern and usage when implementing educational innovations (Hord \& Thurber, 1991).

\section{METHODOLOGY}




\section{Research Question 1}

What are the two highest stages of concern for librarians, library science educators, and library science students' regarding the readiness for teacher librarianship education in Germany?

\section{Research Question 2}

What are librarians, library science educators, and library science students' feelings and knowledge regarding the readiness for teacher librarianship education in Germany?

Stages of Concern Protocol

In order to answer the research questions, the study integrated a widely used and validated protocol with a strong research base- the Concerns Based Adoption Model (CBAM) - as a framework, and the Stages of Concern Questionnaire (SoCQ) in CBAM as an instrument. The term "concern" does not mean simply someone's psychological state or cognition. The concept of concern has a broader meaning, and the operational definition of concern in the CBAM is the composite representation of humans' feelings and knowledge about a specific event or issue. Furthermore, it includes an individual's human experience - including attitudes, concerns and beliefs (Buckner, 2013) referring to "questioning, analyzing, and re-analyzing, considering alternative actions and reactions, and anticipating consequences" (Hall \& Hord, 2011, p. 72). It is clear that the CBAM is not only a simple tool to describe the process of individuals who experience an innovation, but also a comprehensive tool to determine "how to plan for and manage change more efficiently and effectively" (Hord et al., 2006, p. 74).

The SoC model assumes that every user or potential user involved in a change has some degree of concern across all seven stages. However, each individual may experience different intensity levels at each stage of concern. The SoCQ is comprised of 35 items - seven stages of concerns with five items respectively. Each item has eight scales ranging from " 0 -- This statement is not true of me." to "7-- This statement is very true." With the cooperation of several German librarian colleagues, the SoCQ was translated into German. The SoCQ was conducted online using Qualtrics software and used to make a diagnosis of the concerns of three groups of stakeholders - librarians, library science educators, and library science students.

Subjects were recruited from three German universities via three faculty members who sent emails to their students and faculty with a link to the CBAM survey, encouraging participation. Students were recruited via personal talks on two campuses. I joined the online listserv, Forum Oeffentliche Bibliotheken, giving me access to the librarian population nationwide. The survey was open from March 21 to May 10, 2016. The total usable responses were 183, as several incomplete surveys were eliminated. Data Analysis

In order to calculate the intensity of concern at each stage, a three-step process was used. First, each stage's sum was aggregated from the scores for all five items. For example, items 3, 12, 21, 23, and 30 belong to Stage 0 . To find the total for Stage 0, the total score of item 3, 12, 21, 23, and 30 was added together. Second, the average score was calculated by dividing the sum of raw scores by the number of the total participants. Lastly, the resulting percentiles were determined by the Raw Score to Percentile Conversion Table providing the prior percentiles for each stage by Hall, George, \& Rutherford (1977). The percentiles of the different levels of concern will be calculated by matching the average score of each stage to the established percentiles. These percentile scores enable the researcher to obtain the SoCQ profile.

\section{Participants}

\section{FINDINGS}

The participants were from various employment backgrounds, ages, levels of education, and states in Germany. The highest numbers of participants are teacher librarians (65 or 36\%), followed by public librarians (46 or $25 \%$ ), academic librarians (30 or $16 \%$ ), other (26 or 14\%), library science students (13 or $7 \%$ ), and library science faculty ( 3 or $2 \%$ ). Respondents' average age is 44 years old with the majority falling in the middle age. No respondents were over 65 years of age.

An applied sciences (undergraduate) degree is the required credential for librarians in Germany and this was the predominant level of education (42\%) reported. German librarians may also receive a 
master's degree at one university - Humboldt University. $33 \%$ of all respondents have this degree, which is higher than expected, but may be due to the fact that I was based at this university. Smaller numbers are for high school (12\%), advanced degree (8\%), below high school (3\%) and other (2\%).

The respondents come from almost all of the states in Germany with the exception of Bremen and Saarland. The most prevalent states where respondents reside are those containing urban areas Nordrhein-Westfalen (18\%), Berlin (14\%) and Hessen (10\%), which is to be expected.

Research Question 1: Highest stages of concern regarding the readiness for teacher librarianship education

The highest stage of concern in the Concerns-Based Adoption Model (CBAM) is referred to as the peak stage and represents the stage with the highest intensity among the seven stages of concern. The peak stage is a measure of the most intense concern that the participants felt about teacher library education at this point in time. In the context of the CBAM, percentiles are not absolute, but rather relative to other stages' scores (George, Hall \& Stiegelbauer, 2013). Additional insight into the dynamics of concerns can be developed by analyzing the second highest stage score in addition to the peak score. The developers (George, et. al, 2013) note that the second highest Stage of Concern will often be adjacent to the highest one.

The Stages of Concern profile for each of the representative groups can be seen in Figure 1. Each of the six follows almost an identical pattern with the peak score in Stage 0 (unconcerned) and the second highest score in Stage 1 (informational). This is the most consistently identified concerns profile - the typical Nonuser. High scores in Stage 0 indicate the degree of priority that the individual is placing on the innovation and the degree of interest in and engagement with the innovation in comparison with other tasks. The higher the Stage 0 score, the more the respondent is indicating that there are a number of other tasks and activities that are of concern to him or her. In other words, the innovation is not the only thing the respondent is concerned about (George, et. al, 2013). This would most likely be the case with teacher librarianship education, which for many of the respondents may have been presented to them for the first time in this survey.

Nonusers' concerns normally are highest on Stages 0, 1, and 2 and lowest on Stages 4, 5 and 6. The profiles of the German library community show high Stages 1 and 2 and it can be inferred that the members are interested in learning more about the innovation. They do not have significant management concerns (Stage 3) and they are not intensely concerned about the consequences of teacher librarianship education (Stage 4). The profiles tail up in the Collaboration Stage (Stage 5) indicating that the respondents want to share ideas with others about teacher librarianship education. They answered positively to questions such as: "I would like to familiarize other departments or people with the progress of this new approach if it were implemented" and "I would like to coordinate my effort with others to maximize teacher librarianship education." The Refocusing Stage (Stage 6), whereby respondents indicate whether they have additional ideas to make the innovation work better, is moderate. 


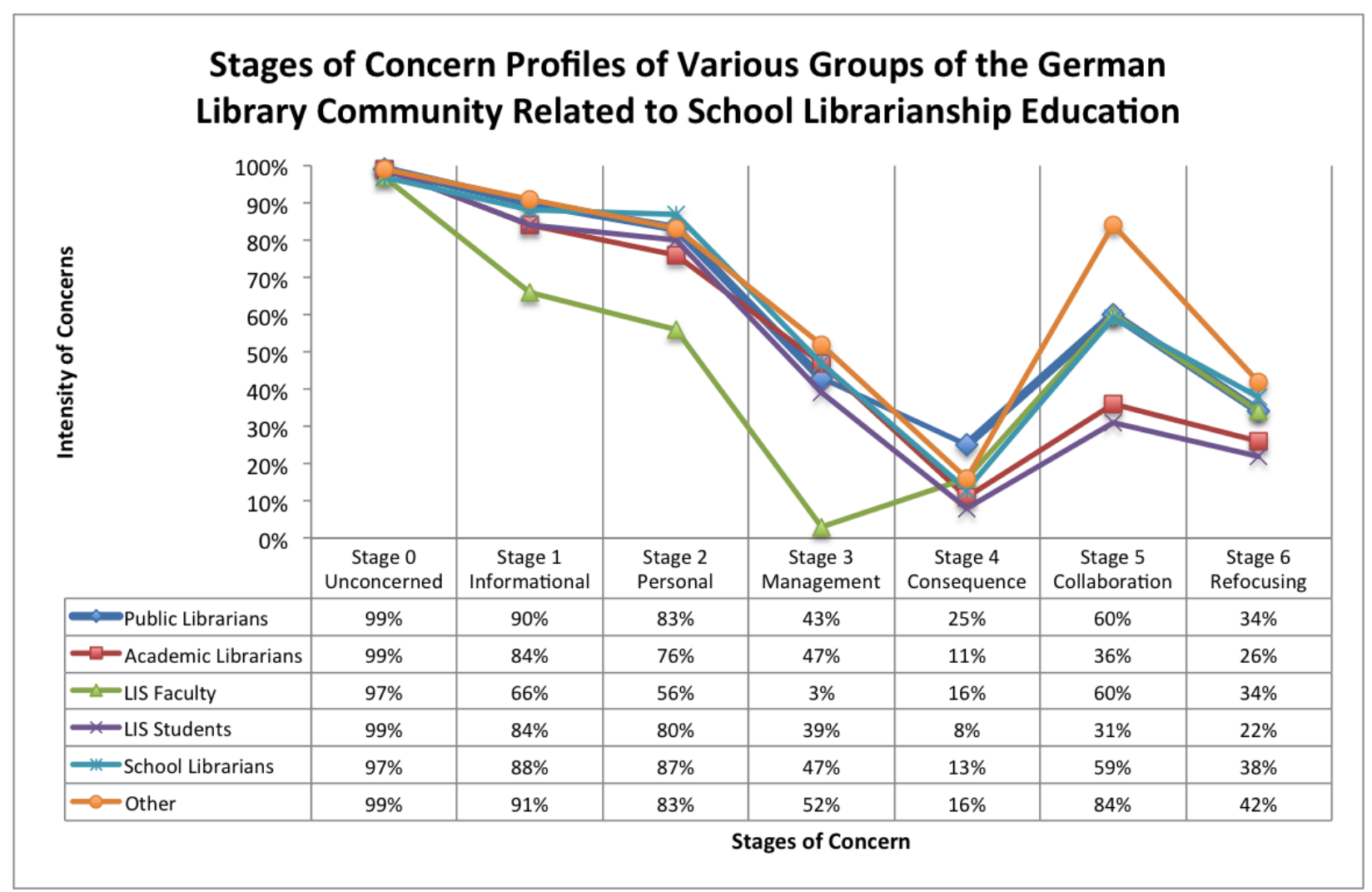

Figure 1: Comparison between the SoC profiles of public librarians, academic librarians, LIS faculty, LIS students, teacher librarians and others

Research Question 2: Feelings and knowledge regarding the readiness for teacher librarianship education

The purpose of this research question is to ascertain both prior knowledge about school libraries and future action steps as to the establishment of teacher librarianship education. As shown in Figure 2, $83 \%$ of the respondents know about or have used school libraries with $50 \%$ believing that school libraries should be established in Germany. A very small number had never visited a school library (3\%) or had no experience with school libraries (3\%). Another 10\% did not use school libraries as a student and 2\% had only read about school libraries. One can conclude that there is vast knowledge about school libraries and a positive reception to establishing them. 


\section{Experience with School Libraries \\ $\mathrm{N}=174$}

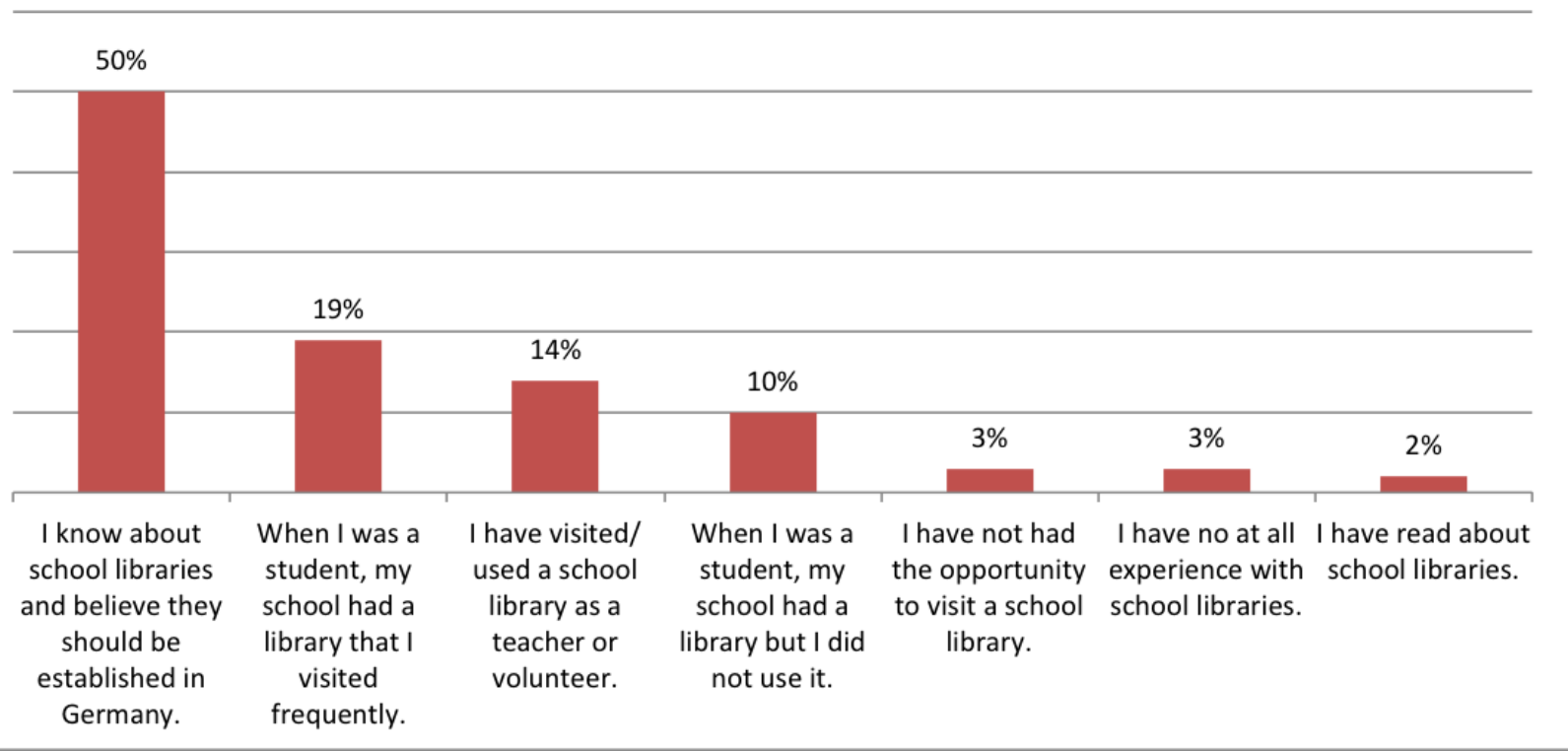

Figure 2: Respondents' experience with school libraries

The overwhelming positive response to the statement about PISA scores, "Schools having a school library with a teacher librarian could potentially raise PISA scores" was enlightening. 78\% believe that school libraries/teacher librarians have potential to increase PISA scores. Another $10 \%$ also believe they do, but only slightly, and not enough to warrant the expense. Only $12 \%$ believe there would be no effect and no one predicted a decrease in scores. Not one person (0\%) was unfamiliar with PISA, proving the importance of this international assessment in Germany. This connection may provide an inroad for discussions on the establishment of school libraries and educating teacher librarians.

Figure 3 presents the responses to questions about opinions on what teacher librarianship education should be. A majority (29\%) favors establishing 2-3 specific school library courses in the undergraduate library education program- similar to the model used in the U.S at the master's level. $18 \%$ would like to see an entire bachelor's degree in school librarianship. There is also support for integrating teacher librarianship courses in teacher education programs $-9 \%$ are in favor of one course and $7 \%$ are in favor of 2-3 courses. Another $10 \%$ value a post high school certificate. Only $3 \%$ believed there is no need for teacher librarianship education. 


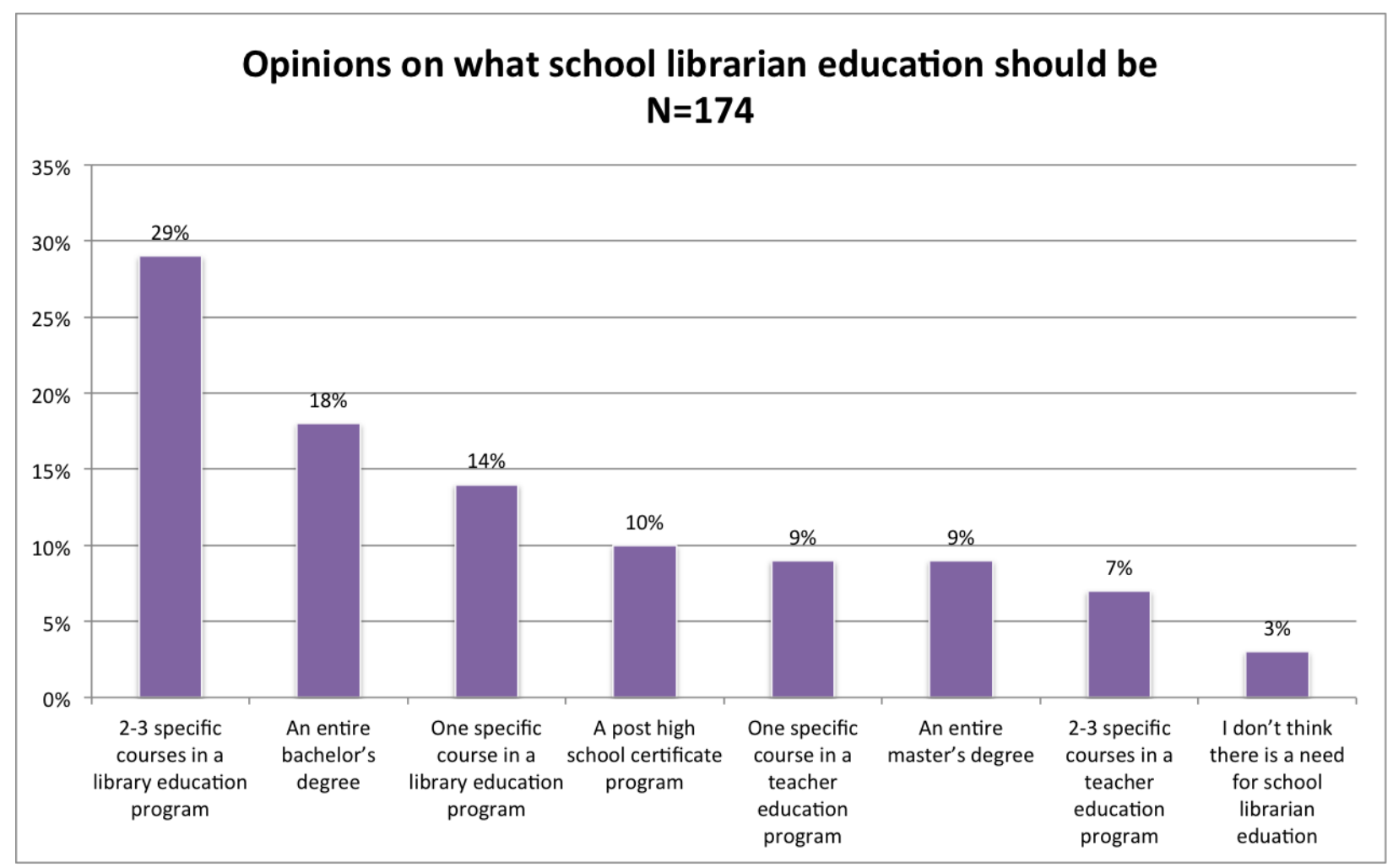

Figure 3: Descriptions of a possible teacher librarian education curriculum

Respondents are eager to get involved in teacher librarianship education if it were to be established. They would actively recommend potential students $(37 \%)$, enroll themselves $(24 \%)$ or want to be an instructor (25\%). Only $13 \%$ said they would do nothing. This enthusiasm bodes well if teacher librarianship education would be established.

\section{CONCLUSIONS}

The administration of the Stages of Concern Questionnaire with a sample of German librarians, students, faculty constructs knowledge about how teacher librarianship education might be received. Many of the participants were presented with the "innovation" of teacher librarianship education for the first time in this survey thus generating a profile of Nonuser - someone who has other priorities at this time. The profiles of the German library community also show high Stages 1 and 2 and it can be inferred that the members are interested in learning more about teacher librarianship education. The profiles in the Collaboration Stage (Stage 5) reveal a community eager to share ideas about teacher librarianship education if might be established.

Substantial knowledge about school libraries and their potential to impact change in German schools was evident in the responses. Traditional teaching and reading appreciation roles for teacher librarians were noted as most important, but a high percentage also felt that PISA scores could be raised having teacher librarians and school libraries.

The participants deem teacher librarianship education to be very much needed and that it could be incorporated into existing library education programs by introducing 2-3 specific courses. The German library community is enthusiastic about the possibility this education could provide to its students and plan to get involved personally or recommend it to others.

\section{REFERENCES}

Buckner, J. W. (2013). Elementary principals' perception of Response to Intervention (RtI) implementation in North Carolina: An exploratory study. Unpublished doctoral dissertation, University of North Carolina, Chapel Hill. 
Dankert, B. (2005). The leaning tower of PISA: School libraries in Germany and Austria. BuB, 55(5), 314-319.

Döbert H. \& Sroka, P. (2004). Features of successful school systems: A comparison of schooling in six countries. Munster, Germany: Waxxmann.

Everhart, N. (2009). Studying school libraries in Germany. Retrieved June 16, 2016, from http://www.ifla.org/en/publications/newsletters-13

George, A., Hall, G. \& Stiegelbauer, S. (2013). Measuring implementation in schools: The stages of concern questionnaire (3rd ed.). Austin, TX: SEDL.

Giersberg, D. (2012). School libraries in Germany: An interview with Julia Rittel. Retrieved June 16, 2016, from http://www.goethe.de/ins/in/en/lp/kul/mag/lut/bib/9606205.html

Hall, G. E., \& Hord, S. M. (2011). Implementing change: Patterns, principles, and potholes (3 ed.). Upper Saddle River, NJ: Pearson Education, Inc.

Hord, S., Rutherford, W., Huling-Austin, L. \& Hall, G. (2006). Taking charge of change (2 ed.). Austin, TX: Southwest Educational Development Laboratory.

Hord, S. \& Thurber, J. (1991). Using the stages of concern model to assess change over time. Retrieved June 17, 2016, from http://www.tandfonline.com/loi/rjie18

Krolak, L. (2006). The role of libraries in the creation of literate environments. Paper commissioned for the EFA Global Monitoring Report 2006, Literacy for Life. Retrieved June 16, 2016, from http://unesdoc.unesco.org/images/0014/001460/146057e.pdf

Krüger, K. (2003). The PISA-shock and its consequences: The future of libraries for children in Germany. Retrieved June 16, 2016, from http://webdoc.sub.gwdg.de/ebook/aw/2003/ifla/.../079e_transKrueger.pdf

Linnakyla, P. \& Valijarvi, J. (2005). Secrets to literacy success: The Finnish story. Education Canada, 45(3), 34-37. Retrieved from www.cea-ace.ca/education-canada

Organisation for Economic Co-operation and Development (OECD) (2010). Germany: Once weak international standing prompts strong nationwide reforms for rapid improvement. In: Strong performers and successful reformers in education: Lessons from PISA for the United States (pp. 201-220). Paris, France: OECD Publishing.

Straub. E. (2009). Understanding technology adoption: Theory and future directions for informal learning. Review of Educational Research 79(2), 625-649.

Weishaupt, H., Scherer, R.,Tarazona, M., Richter, M., Krätschmer-Hahn, R. \& Zimmer, K. (2013). Zur situation kultureller bildung an schulen. Frankfurt am Main: Gesellschaft zur Förderung Pädagogischer Forschung, Deutsches Institut für Internationale Pädagogische Forschung. 